\title{
Intravenous pharmacokinetics, oral bioavailability, dose proportionality and in situ permeability of anti-malarial lumefantrine in rats
}

\author{
Wahajuddin ${ }^{1,2^{*}}{ }^{+}$, Sheelendra P Singh ${ }^{1 \dagger}$, Kanumuri SR Raju$^{2}$, Asad Nafis ${ }^{2}$, Sunil K Puri ${ }^{3}$ and Girish K Jain
}

\begin{abstract}
Background: Despite the wide spread use of lumefantrine, there is no study reporting the detailed preclinical pharmacokinetics of lumefantrine. For the development of newer anti-malarial combination(s) and selection of better partner drugs, it is long felt need to understand the detailed preclinical pharmacokinetics of lumefantrine in preclinical experimental animal species. The focus of present study is to report bioavailability, pharmacokinetics, dose linearity and permeability of lumefantrine in rats.
\end{abstract}

Methods: A single dose of 10,20 or $40 \mathrm{mg} / \mathrm{kg}$ of lumefantrine was given orally to male rats ( $\mathrm{N}=5$ per dose level) to evaluate dose proportionality. In another study, a single intravenous bolus dose of lumefantrine was given to rats $(\mathrm{N}=4)$ at $0.5 \mathrm{mg} / \mathrm{kg}$ dose following administration through the lateral tail vein in order to obtain the absolute oral bioavailability and clearance parameters. Blood samples were drawn at predetermined intervals and the concentration of lumefantrine and its metabolite desbutyl-lumefantrine in plasma were determined by partially validated LC-MS/MS method. In-situ permeability study was carried in anaesthetized rats. The concentration of lumefantrine in permeability samples was determined using RP-HPLC.

Results: For nominal doses increasing in a 1:2:4 proportion, the $C_{\max }$ and $A \cup C_{0-\infty}$ values increased in the proportions of 1:0.6:1.5 and 1:0.8:1.8, respectively. For lumefantrine nominal doses increasing in a 1:2:4 proportion, the $C_{\max }$ and the $A \cup C_{0-t}$ values for desbutyl-lumefantrine increased in the proportions of 1:1.45:2.57 and 1:1.08:1.87, respectively. After intravenous administration the clearance $(\mathrm{Cl})$ and volume of distribution $(\mathrm{Vd})$ of lumefantrine in rats were $0.03( \pm 0.02) \mathrm{L} / \mathrm{h} / \mathrm{kg}$ and $2.40( \pm 0.67) \mathrm{L} / \mathrm{kg}$, respectively. Absolute oral bioavailability of lumefantrine across the tested doses ranged between $4.97 \%$ and $11.98 \%$. Lumefantrine showed high permeability $\left(4.37 \times 10^{-5}\right.$ $\mathrm{cm} / \mathrm{s}$ ) in permeability study.

Conclusions: The pharmacokinetic parameters of lumefantrine and its metabolite desbutyl-lumefantrine were successfully determined in rats for the first time. Lumefantrine displayed similar pharmacokinetics in the rat as in humans, with multiphasic disposition, low clearance, and a large volume of distribution resulting in a long terminal elimination half-life. The absolute oral bioavailability of lumefantrine was found to be dose dependent.

Lumefantrine displayed high permeability in the in-situ permeability study.

\section{Background}

According to the World Health Organization (WHO), there were in 2008 an estimated 247 million malaria cases among more than 3 billion people at risk, causing nearly one million deaths (even much more according

\footnotetext{
* Correspondence: wahajuddin@gmail.com

+ Contributed equally

'Pharmacokinetics and Metabolism Division, CSIR-Central Drug Research

Institute, Lucknow-226001, Uttar Pradesh, India

Full list of author information is available at the end of the article
}

to other estimates), mostly of children under 5 years and pregnant women [1]. The burden of malaria disease continues to increase as the countries in which it is endemic face the risk of widespread resistance of the parasite to conventional anti-malarial drugs and increasing resistance of the vector to insecticide. Artemether/ lumefantrine $\left(\mathrm{AL}\right.$; Coartem $\left.{ }^{\circledR}\right)$ is an artemisinin-based combination therapy (ACT) that offers PCR-corrected 28-day cure rates of $>95 \%$ [2-9], if given in a six-dose regimen. AL meets the WHO pre-qualification criteria 
for efficacy, safety and quality and is the only ACT that has been approved by ICH stringent regulatory authorities [10].

Despite the potency of artemether, 100-100,000 residual parasites remain when the drug is used alone for a three-day treatment course, and as a result up to $10 \%$ of patients experience recrudescence [11,12]. It was recognized that combination treatment, which eliminated the final parasites, would be advantageous. Lumefantrine, the other active constituent of AL, acts over a longer period to eliminate the residual $100-100,000$ parasites that remain after artemether is cleared from the body and thus minimizes the risk of recrudescence. Artemether and lumefantrine have different modes of action and act at different points in the parasite life cycle $[13,14]$. Artemisinin derivatives, such as artemether, have multiple mechanisms of action, including interference with parasite transport proteins, disruption of parasite mitochondrial function, modulation of host immune function and inhibition of angiogenesis [15]; Whereas, lumefantrine prevents the detoxification of haem, such that toxic haem and free radicals induce parasite death [13]. Additionally, the differing pharmacokinetics of the two agents offers an advantage for combination therapy. Furthermore, in vitro, artemether and lumefantrine have shown synergistic action against Plasmodium falciparum under in vitro conditions [16].

The anti-malarial agent lumefantrine, which was originally synthesized by the Academy of Military Medical Sciences in Beijing [17], was identified by researchers at the Academy as a promising agent for combination with artemisinin. Lumefantrine, 2-(dibutylamino)-1-[(9E)-2,7dichloro-9-[(4-chlorophenyl) methylidene] fluoren-4-yl] ethanol is an arylamino alcohol [14]. Its molecular weight is $528.939 \mathrm{~g} / \mathrm{mol}$. It is a lipophillic compound with low intrinsic clearance and erratic oral variability and therapeutic levels are more reliably achieved by co-administration with a fatty meal [14,18-22]. Lumefantrine is eliminated very slowly with a terminal half-life of 2-3 days in healthy volunteers and 4-6 days in patients with falciparum malaria $[14,18,23,24]$. Its plasma protein binding is almost $100 \%$ [25]. Lumefantrine is predominantly, metabolized by cytochrome P450 3A4 (CYP3A4), to desbutyl lumefantrine (DLF). The in vitro antiparasitic effect of desbutyl- lumefantrine is 5 to 8 fold higher than lumefantrine [26].

Recently, Wong et al [27] reported that DBL has potential as an anti-malarial drug in its own right. Its in vitro potency relative to that of the parent compound (lumefantrine), its synergy with dihydroartemisinin and the positive relationship between day 7 plasma concentrations and adequate clinical and parasitological response (ACPR) suggest that it could be a useful alternative to lumefantrine as a part of artemisinin-based combination therapy (ACT).
The limitation of artemether-lumefantrine combination is the side effects associated with artemether, i.e hearing impairment, its high cost, and its variable absorption and the strong food effect on the pharmacokinetics of lumefantrine. Development of newer antimalarial combinations require detailed preclinical pharmacokinetic assessment of combination partner drugs separately as well as in combination for better understanding of their efficacy, toxicity and safety profile before going in to clinical studies. Preclinical pharmacokinetic information is also very useful in dose/dosage regimen selection of combination partner drugs for clinical assessment. For the development of newer antimalarial combination(s) and selection of better partner drugs, it is long felt need to understand the detailed preclinical pharmacokinetics of existing combination drugs (viz. lumefantrine, artemether etc.) in preclinical experimental animal species.

All the studies reporting pharmacokinetics of lumefantrine dealt with clinical data. Despite the wide spread clinical use of lumefantrine, there is no study reporting the detailed preclinical pharmacokinetics. However, the preclinical pharmacokinetics of artemether in rats has been reported very recently [28]. The focus of present study is to report bioavailability, pharmacokinetics, dose linearity and permeability of lumefantrine. The presence of preclinical pharmacokinetic data in public domain will be of immense help in making informed decisions while selecting the better partner drug(s) for newer combination(s).

\section{Methods}

\section{Chemicals and reagents}

Lumefantrine, desbutyl-lumefantrine and halofantrine (IS) were a generous gift from Ipca Laboratories Ltd. (Mumbai, India). Phenol red and HPLC grade acetonitrile were purchased from Sisco Research Laboratories (SRL) Pvt. Limited (Mumbai, India). HPLC grade n-hexane was obtained from E Merck Limited (Mumbai, India). HPLC grade methanol was purchased from Thomas Baker Pvt. Limited (Mumbai, India). Ammonium acetate, ethanol and glacial acetic acid (GAA) AR were purchased from E Merck Limited (Mumbai, India). Potassium dihydrogen orthophosphate was purchased from New India Chemical Enterprises (Cochin, India). Polyethylene glycol (PEG400) and Carboxy methyl cellulose (CMC) were purchased from Sigma Aldrich Ltd (St Louis, USA). Dimethylformamide was purchased from Thomas Baker (chemicals) Pvt. Limited (Mumbai, India). Urethane was purchased from Thermo Fisher Scientific India Pvt. Ltd. (Mumbai, India). Ultra pure water was obtained from a Sartorious Arium 611 system. Heparin sodium injection I.P. (1000 IU/mL, Biologicals E. Limited, Hyderabad, India) was purchased from 
local pharmacy. Blank, drug free plasma samples were collected from adult, healthy male Sprague-Dawley (SD) rats at the Division of Laboratory Animals (DOLA) of Central Drug Research Institute (Lucknow, India). Plasma was obtained by centrifuging the heparinized blood $(25 \mathrm{IU} / \mathrm{mL})$ at $2000 \times \mathrm{g}$ for $10 \mathrm{~min}$ at $20^{\circ} \mathrm{C}$. Prior approval from the Institutional Animal Ethics Committee (IAEC) was sought for maintenance, experimental studies, euthanasia and disposal of carcass of animals.

\section{Animals}

Young, adult male SD rats, weighing 200-220 g, were procured from the National Laboratory Animal Center, CDRI (Lucknow, India). Rats were housed in well ventilated cages at room temperature $\left(24 \pm 2^{\circ} \mathrm{C}\right)$ and $40-60 \%$ relative humidity while on a regular $12 \mathrm{~h}$ light-dark cycle. The animals were acclimatized for a minimum period of three days prior to the experiment. Approval from the Institutional Animal Ethics Committee was sought and the study protocols were approved before the commencement of the studies.

\section{In-situ permeability studies}

Single-pass intestinal perfusion studies in rats were performed using established methods adapted from the literature [29]. Briefly, male SD rats were fasted overnight for 12 to $16 \mathrm{~h}$ with free access to water and anaesthetized using an intra-peritoneal injection of urethane (1 $\mathrm{g} / \mathrm{kg}$ ) and placed on a heated pad to keep normal body temperature. Upon verification of the loss of pain reflex, a midline longitudinal abdominal incision was made, and the lumen of the jejunum $(10 \mathrm{~cm})$ was flushed with $10 \mathrm{ml}$ of saline pre-warmed to $37^{\circ} \mathrm{C}$. The proximal end of the lumen was catheterized with an inlet polypropylene tube, which was connected to a perfusion pump. The distal end of the jejunum was also catheterized with an outlet polypropylene tube to collect intestinal effluent. Care was taken to handle the small intestine gently and to minimize the surgery in order to maintain an intact blood supply. The entire excised area was covered with an absorbable cotton pad soaked in warmed normal saline. After allowing $30 \mathrm{~min}$ to reach steady-state outlet concentrations, outlet perfusate samples were collected every $15 \mathrm{~min}$ for $120 \mathrm{~min}$ perfusion period. Phenol red was used as a marker of osmosis/zero permeability. At the end, the length of segment was measured without stretching and finally the animal was euthanized. Samples were stored at $-20^{\circ} \mathrm{C}$ until analysis.

\section{HPLC analysis of In-situ permeability samples}

The concentration of lumefantrine and phenol red in permeability samples was determined by high-performance liquid chromatography (HPLC) coupled with PDA detector. Chromatographic separation was performed on a Supelco Discovery C18 column $(4.6 \times$ $150 \mathrm{~mm}, 5.0 \mu \mathrm{m})$. Mobile phases were duly filtered through $0.22 \mu \mathrm{m}$ Millipore filter (Billerica, USA) and degassed ultrasonically for $15 \mathrm{~min}$ and then were pumped in gradient mode. The detail of the gradient program is given in Table 1 . The lumefantrine and phenol red were detected at the wavelength of 235 and 420 $\mathrm{nm}$, respectively.

\section{Permeability data analysis}

The single pass intestinal perfusion is based on reaching steady state with respect to the diffusion of compound across intestine. Steady state is confirmed by plotting the ratio of the outlet to inlet concentrations (corrected for water transport) versus time. The outlet concentrations were corrected by multiplying the inlet concentration with $[\mathrm{phenol} \mathrm{red}]_{\text {in }} /[\mathrm{phenol} \mathrm{red}]_{\text {out }}$. Permeability calculations across rat jejunum $\left(P_{\text {eff }}\right)$ were performed from intestinal perfusate samples collected over 30-120 min (steady state).

$[\mathrm{phenol} \mathrm{red}]_{\text {in }}$ and $[\mathrm{phenol} \mathrm{red}]_{\text {out }}$ are the inlet and outlet concentrations of the water flux marker phenol red. The effective permeability coefficient $\left(P_{\text {eff }}\right)$ and drug absorption rate constant $\left(K_{a}\right)$ were calculated using the following equations:

$$
\begin{gathered}
P_{\text {eff }}=\frac{-Q_{\text {in }} \ln \left[\frac{C_{\text {out }}}{C_{\text {in }}}\right]}{2 \pi \mathrm{r} l} \\
K_{a}=\left[1-\frac{C_{\text {out }}}{C_{\text {in }}}\right] \times \frac{Q_{\text {in }}}{\pi r^{2} l}
\end{gathered}
$$

Where, $C_{\text {out }}$ is the corrected concentration of the permeant in the exiting perfusate; $C_{i n}$ is the concentration of the permeant in entering perfusate; $Q_{i n}$ is the flow rate of entering perfusate $(0.2 \mathrm{~mL} / \mathrm{min}) ; r$ is the inner radius of the intestine, which is $0.18 \mathrm{~cm} \mathrm{[30];} \mathrm{and} l$ is the length of the intestine.

\section{Pharmacokinetic studies}

Dose proportional oral pharmacokinetic studies

Male SD rats weighing 200-220 g were fasted overnight (12-14 h) before dosing and had free access to water

Table 1 HPLC gradient used for the determination of lumefantrine and phenol red in in-situ permeability samples

\begin{tabular}{cccc}
\hline $\begin{array}{c}\text { Time } \\
\text { (Minute) }\end{array}$ & Solvent A & Solvent B & $\begin{array}{c}\text { Flow rate } \\
(\mathbf{m L} / \mathbf{m i n})\end{array}$ \\
\hline $0-4$ & 65 & 35 & 1 \\
$4-12$ & 30 & 70 & \\
$12-17$ & 65 & 35 & \\
\hline
\end{tabular}

Solvent $\mathrm{A}: \mathrm{KH}_{2} \mathrm{PO}_{4}$ buffer (10 mM, pH-3)

Solvent B: Methanol 
throughout the experimental period. Lumefantrine in $0.25 \%$ CMC suspension was administered orally at a dose of $10,20 \& 40 \mathrm{mg} / \mathrm{kg}$ to groups of five rats at each dose level. Animals were provided with standard diet 3 $\mathrm{h}$ after dosing. The rats were anaesthetized using ether and blood samples (approximately $0.25 \mathrm{~mL}$ ) were collected from the retro-orbital plexus into heparinized microfuge tubes at $0.5,2,5,8,24,30,48,54,72$ and $120 \mathrm{~h}$ post-dosing. Plasma was harvested by centrifuging the blood at $13000 \mathrm{rpm}$ for $10 \mathrm{~min}$ on Sigma 1-15 K (Frankfurt, Germany) and stored frozen at $-70 \pm 10^{\circ} \mathrm{C}$ until bioanalysis.

\section{Intravenous pharmacokinetic study}

Another group of male SD rats $(\mathrm{N}=4)$ weighing 200$220 \mathrm{~g}$, were used in this part of the study. The intravenous formulation was prepared in DMF-PEG 400-ethanol-water (5: 2.5: $1: 1.5 \mathrm{v} / \mathrm{v}$ ) and finally filtered through $0.22 \mu \mathrm{m}$ filter before administration. The solution of lumefantrine was administered to rats via a lateral tail vein as a bolus dose of $0.5 \mathrm{mg} / \mathrm{kg}$. Animals had free access to food and water throughout the experimentation period. Blood samples (approximately $0.25 \mathrm{~mL}$ ) were collected from the retro-orbital plexus into heparinized microfuge tubes at $0.08,0.5,2,4,6,25,30,48,54$, 72,96 and $120 \mathrm{~h}$ post-dosing and plasma was harvested by centrifuging the blood at $13000 \mathrm{rpm}$ for $10 \mathrm{~min}$ and stored frozen at $-70 \pm 10^{\circ} \mathrm{C}$ until bioanalysis.

\section{Sample preparation}

A simple liquid-liquid extraction method was followed for extraction of lumefantrine and desbutyl-lumefantrine from rat plasma. To $100 \mu \mathrm{L}$ of plasma in a tube, $10 \mu \mathrm{L}$ of IS solution (halofantrine at $1 \mu \mathrm{g} / \mathrm{mL}$ in methanol), 50 $\mu \mathrm{L}$ of GAA, $50 \mu \mathrm{L}$ of phosphate buffer $(50 \mathrm{mM}, \mathrm{pH} 3)$ were added and mixed for $15 \mathrm{~s}$ on a cyclomixer (Spinix Tarsons, Kolkata, India). Next a $2 \mathrm{~mL}$ aliquot of extraction solvent, $\mathrm{n}$-hexane was added. The mixture was then vortexed for $3 \mathrm{~min}$, followed by centrifugation for $5 \mathrm{~min}$ at $2000 \times$ g at $20^{\circ} \mathrm{C}$ on Sigma 3-16 K (Frankfurt, Germany). The organic layer $(1.6 \mathrm{~mL})$ was separated and evaporated to dryness under vacuum in speedvac concentrator (Savant Instrument, Farmingdale, USA). The residue was reconstituted in $200 \mu \mathrm{L}$ of the mobile phase and $10 \mu \mathrm{L}$ of this solution was subjected to LC-MS/MS analysis.

\section{LC-MS/MS analysis of lumefantrine and desbutyl- lumefantrine in study samples}

Plasma concentrations of lumefantrine and desbutyllumefantrine were determined using partially validated LC-MS/MS method that was accurate, precise, specific, sensitive and reproducible. Analyses were carried out using a HPLC system consists of Series 200 pumps and auto sampler with temperature controlled Peltier-tray
(Perkin-Elmer instruments, Norwalk, USA) on a XBridge RP18 column $(4.6 \times 50 \mu \mathrm{m}, 5.0 \mu \mathrm{m})$. The system was run in isocratic mode with mobile phase consisting of acetonitrile: methanol $(50: 50, \mathrm{v} / \mathrm{v})$ and $0.01 \mathrm{M}$ ammonium acetate $(\mathrm{pH} 4.5)$ in the ratio of $95: 5(\mathrm{v} / \mathrm{v})$ at a flow rate of $0.65 \mathrm{~mL} / \mathrm{min}$. Mass spectrometric detection was performed on an API 4000 mass spectrometer (Applied Biosystems, MDS Sciex Toronto, Canada) equipped with an API electrospray ionization (ESI) source. The mass spectrometer was operated at ESI positive ion mode and detection of the ions was performed in the multiple reaction monitoring (MRM) mode, monitoring transition of $\mathrm{m} / \mathrm{z} 529$ precursor ion $[\mathrm{M}+\mathrm{H}]^{+}$to the $\mathrm{m} / \mathrm{z} 511.3$ product ion for lumefantrine, $\mathrm{m} / \mathrm{z} 472.1$ precursor ion $[\mathrm{M}+\mathrm{H}]^{+}$to the $\mathrm{m} / \mathrm{z} 454.1$ product ion for desbutyl lumefantrine and $\mathrm{m} / \mathrm{z} 502$ precursor ion $[\mathrm{M}+\mathrm{H}]^{+}$to the $\mathrm{m} / \mathrm{z} 511.3$ product ion for IS. Data acquisition and quantitation were performed using analyst software version 1.4.1 (Applied Biosystems, MDS Sciex Toronto, Canada). The retention times for lumefantrine, desbutyllumefantrine and IS were 4.81, 2.61 and $2.30 \mathrm{~min}$, respectively. The lower limit of quantification of the method was $2 \mathrm{ng} / \mathrm{mL}$ and linearity in the calibration curve standards were demonstrated up to an upper limit of $500 \mathrm{ng} / \mathrm{mL}$. Prior to the analysis of samples, three concentrations (nominal concentrations of 8, 180 and $400 \mathrm{ng} / \mathrm{mL}$ ) of quality control (QC) samples were prepared in rat plasma. Along with the study samples, QC samples $(\mathrm{N}=4$, at each concentration level) were distributed among the unknown samples in the analytical run.

\section{Pharmacokinetic analysis}

Plasma data were subjected to non-compartmental pharmacokinetics analysis using WinNonlin (version 5.1, Pharsight Corporation, Mountain View, USA). The observed maximum plasma concentration $\left(C_{\max }\right)$ and the time to reach the maximum plasma concentration $\left(T_{\max }\right)$ were obtained by visual inspection of the experimental data. The area under the plasma concentration time curve $\left(\mathrm{AUC}_{0-\mathrm{t}}\right)$ was calculated using linear trapezoidal method. The total area under the plasma concentration-time curve from time zero to time infinity $\left(\mathrm{AUC}_{0-\infty}\right)$ was calculated as the sum of $\mathrm{AUC}_{0-\mathrm{t}}$ and $\mathrm{C}_{\text {last }} / \mathrm{kel}$, where, $\mathrm{C}_{\text {last }}$ represents the last quantifiable concentration and Kel represents the terminal phase rate constant. The apparent elimination half-life $\left(t_{1 / 2}\right)$ was calculated as $0.693 / \mathrm{kel}$ and the kel was estimated by linear regression of the plasma concentrations in the log-linear terminal phase. Clearance $(\mathrm{CL})$ following i.v. dosing was calculated as Dose/AUC $\mathrm{A-}_{-\infty}$. The apparent volume of distribution ( $\mathrm{Vd}$ ) was given by the quotient between $\mathrm{CL}$ and elimination rate constant kel following administration of the intravenous bolus dose. 
The absolute bioavailability (\%F) of lumefantrine was calculated using the relationship,

$\% \mathrm{~F}=\left[\operatorname{AUC}_{(0-\infty) \text { oral }} \times\right.$ Dose $($ i.v. $) / \operatorname{AUC}_{(0-\infty) \text { i.v. }} \times$ Dose $($ oral $\left.)\right] \times 100$

\section{Results and discussion \\ Analytical results}

The rat plasma samples generated following oral and intravenous administration of lumefantrine were analyzed by the partially validated method along with QC samples. Linearity, specificity \& selectivity, recovery, matrix effect and accuracy \& precision were measured and used as the parameter to assess the assay performance. The peak area ratios of analytes to internal standard in rat plasma were linear over the concentration range $2-500 \mathrm{ng} / \mathrm{ml}$ for both the analytes. The choice of the regression methods was determined. Both lumefantrine and desbutyl-lumefantrine data fit well with a linear regression model, and weighting of $1 /$ concentration $^{2}$. The correlation coefficients of the standard curves for lumefantrine and desbutyl-lumefantrine, ranging from 2 to $500 \mathrm{ng} / \mathrm{ml}$, were all > 0.996. LC-MS/MS analysis of the blank plasma samples showed no interference with the quantification of lumefantrine, desbutyl lumefantrine and IS (Figure-1). The extraction recovery of analytes, was determined by comparing the peak areas of extracted plasma (prespiked) standard QC samples $(\mathrm{N}=6)$ to those of the post-spiked standards at equivalent concentrations [31]. The effect of rat plasma constituents over the ionization of analytes and IS was determined by comparing the responses of the post-extracted plasma standard QC samples $(\mathrm{N}=6)$ with the response of analytes from neat standard samples at equivalent concentrations [31]. The recovery and matrix effect testing was performed at three concentrations QC low, QC medium and QC high concentrations viz., 8, 180, and 400 $\mathrm{ng} / \mathrm{mL}$ for analytes, whereas the recovery and matrix effect of the IS were determined at a single concentration of $50 \mathrm{ng} / \mathrm{mL}$. The extraction recoveries of the lumefantrine and desbutyl-lumefantrine ranged from 70.45 to $80.12 \%$, and the extraction recovery of the internal standard was $73.31 \%$. The ion suppression or enhancement by plasma was less than $12 \%$ for the analytes and IS which demonstrated that the matrix effects do not cause quantitation bias.

\section{(A) Rat blank plasma}

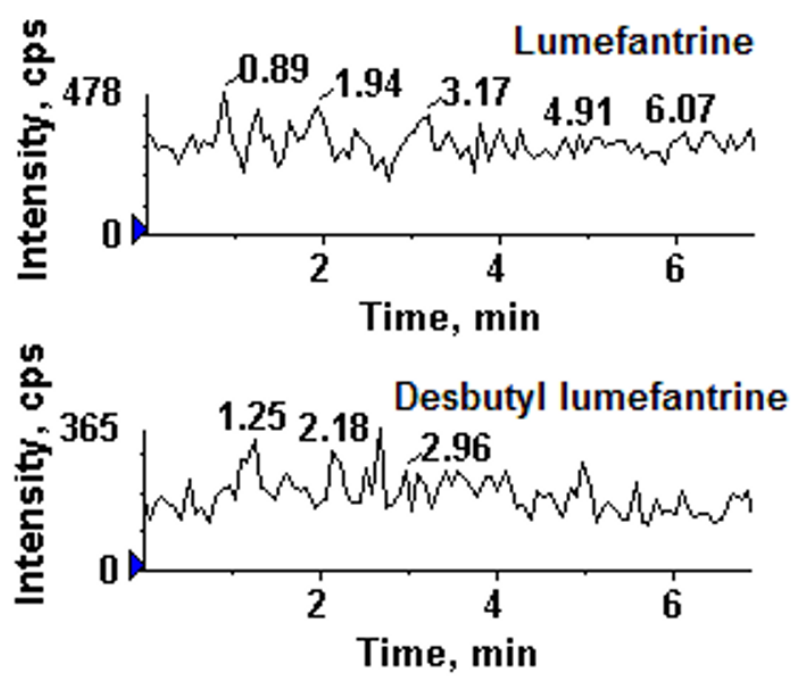

\section{(B) LLOQ}
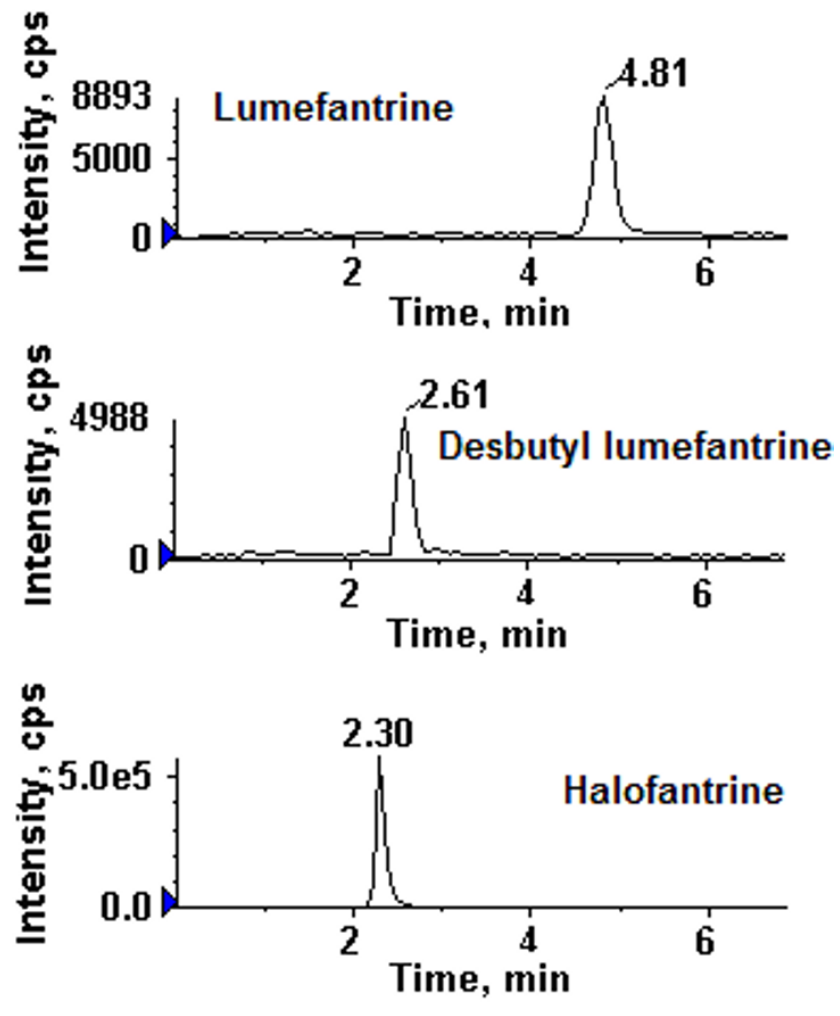

Figure 1 Typical multiple reaction monitoring chromatograms of lumefantrine and desbutyl lumefantrine in rat plasma (A) Rat blank plasma, (B) drug free plasma spiked with lumefantrine and desbutyl-lumefantrine at LLOQ $(2 \mathrm{ng} / \mathrm{mL})$ and halofantrine (IS). 
The intra-day assay precision and accuracy were estimated by analyzing six replicates at four different QC levels, i.e., $2 \mathrm{ng} / \mathrm{mL}$ (lower limit of quantitation, LLOQ), 8 (QC low), $180 \mathrm{ng} / \mathrm{mL}$ (QC medium) and $400 \mathrm{ng} / \mathrm{mL}$ (QC high). The inter-day assay precision was determined by analyzing the four levels QC samples on three different runs. The intra- and inter-day assay precision ranged from 3.74 to $7.63 \%$ and 5.79 to $7.32 \%$ (R.S.D. \%), respectively, and intra- and inter-day assay accuracy were between 95.28 to $105.46 \%$ and 96.51 to $105.09 \%$, respectively for both the analytes. The mean predicted concentrations of QC samples (distributed among the unknown samples) were between $89.98-107.56 \%$ of the nominal values.

\section{In-situ permeability study}

In-situ perfusion of intestinal segments of rodents (rats or rabbits) is frequently used to study the permeability and absorption kinetics of drugs. The $P_{\text {eff }}$ values of lumefantrine was determined as the average of six 15 min sampling periods starting from $30 \mathrm{~min}$ after the initiation of perfusion, when steady-state had been achieved. Phenol red was used as non-absorbable marker for correction of water flux. During in-house permeability study of amongst USFDA approved high permeability markers, metoprolol showed minimum permeability in rat jejunum $\left(1.88 \times 10^{-5} \mathrm{~cm} / \mathrm{s}\right)$. $P_{\text {eff }}$ value of lumefantrine was found to be $4.37 \times 10^{-5} \mathrm{~cm} / \mathrm{s}$ which is greater than metoprolol permeability. Therefore, lumefantrine can be classified under high permeability class of BCS (biopharmaceutical classification system).

\section{Pharmacokinetic study}

The plasma concentrations of lumefantrine were measurable up to $120 \mathrm{hr}$ after oral and intravenous administration. Figure- 2 depicts the mean plasma concentration-time profiles of lumefantrine following single oral and intravenous administration to male SD rats. The mean oral and intravenous pharmacokinetic parameters for lumefantrine are summarized in Table 2. The variability in plasma concentrations between-animals were observed for lumefantrine after oral administration. However, the low between-animal variability in plasma concentrations after intravenous doses suggests absorption to be critical for between-animal variability in drug exposure. This is also seen in clinical use with substantial inter-individual variability in the pharmacokinetics of lumefantrine after oral administration $[14,18]$.

The $\mathrm{T}_{\max }$ of lumefantrine after oral administration was found to be in the range of 2-8 $\mathrm{h}$. The reason for longer $T_{\max }$ seems to be the low aqueous solubility of lumefantrine since, lumefantrine displayed high permeability in the in-situ permeability study. Similarly in humans the $\mathrm{T}_{\max }$ of lumefantrine occurs later, at approximately six hours post-dosing in healthy volunteers and 3-4 hours in malaria patients $[14,18]$.

For nominal doses increasing in a 1:2:4 proportion, the $C_{\max }$ and $\mathrm{AUC}_{0-\infty}$ values increased in the proportions of 1:0.63:1.53 and 1:0.83:1.81, respectively. Both $\mathrm{C}_{\max }$ and $\mathrm{AUC}_{0-\infty}$ values of lumefantrine were not increased proportionally with increment of dose, which could be due to dissolution-limited absorption at higher doses due to low solubility of lumefantrine.

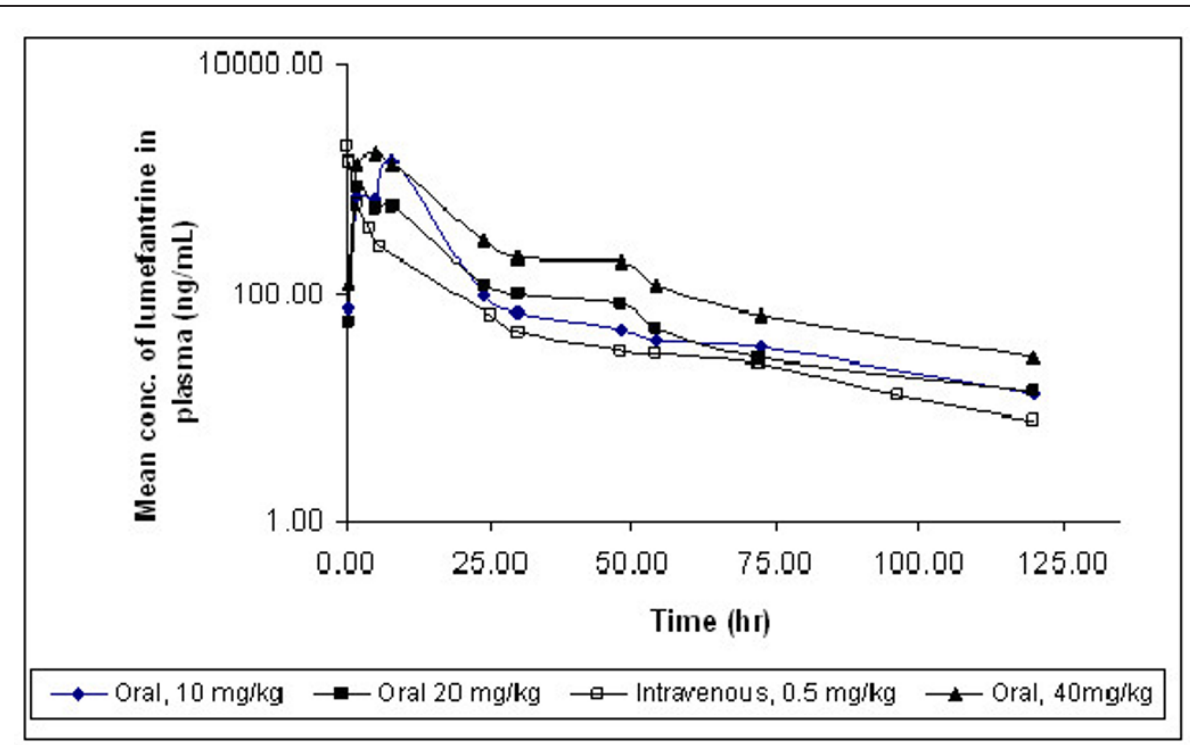

Figure 2 Plasma concentration versus time profiles of lumefantrine after oral and intravenous administration in rats $(\mathrm{N}=5)$. All concentrations are on the logarithmic scale. 
Table 2 Pharmacokinetic parameters of lumefantrine after oral and intravenous administration in rats

\begin{tabular}{|c|c|c|c|c|}
\hline Parameters & Intravenous & Per-oral & & \\
\hline & $0.5 \mathrm{mg} / \mathrm{kg}$ & $10 \mathrm{mg} / \mathrm{kg}$ & $20 \mathrm{mg} / \mathrm{kg}$ & $40 \mathrm{mg} / \mathrm{kg}$ \\
\hline$A U C_{0-t}\left(h r^{*} n g / m L\right)$ & $9,189.76 \pm 1,372.42$ & $21,294.02 \pm 3,235.75$ & $17,683.7 \pm 3,168.23$ & $38,248.94 \pm 7,792.61$ \\
\hline$A U C_{0-\infty}\left(h r^{*} n g / m L\right)$ & $9,529.47 \pm 1,283.18$ & $22,025.48 \pm 3,448.87$ & $18,281.07 \pm 3,062.84$ & $39,958.71 \pm 8,362.60$ \\
\hline$C_{\max }(\mathrm{ng} / \mathrm{mL})$ & $1,890 \pm 330.61$ & $1,488 \pm 311.47$ & $938.75 \pm 370.64$ & $2,280 \pm 522.32$ \\
\hline $\mathrm{T}_{\max }(\mathrm{hr})$ & - & $8(2-8)$ & $3.5(2-8)$ & $5(2-8)$ \\
\hline $\mathrm{Vd}(\mathrm{L} / \mathrm{kg})$ & $2.40 \pm 0.67$ & - & - & - \\
\hline $\mathrm{CL}(\mathrm{L} / \mathrm{h} / \mathrm{kg})$ & $0.03 \pm 0.02$ & - & - & - \\
\hline$t_{1 / 2}(h r)$ & $30.92 \pm 4.81$ & $36.08 \pm 8.52$ & $25.7 \pm 1.85$ & $38.23 \pm 4.51$ \\
\hline$\% \mathrm{~F}$ & - & 11.56 & 4.80 & 5.24 \\
\hline
\end{tabular}

The plasma concentrations following intravenous administration of lumefantrine dropped to $45 \%$ in approximately $0.05 \mathrm{~h}$. Following intravenous administration, the $t_{1 / 2}$ was found to be $30.92( \pm 4.81) \mathrm{h}$. $\mathrm{AUC}_{0-\infty}$, clearance (CL) and volume of distribution (Vd) of lumefantrine following administration of $0.5 \mathrm{mg} / \mathrm{kg}$ i.v. were $9529.47( \pm 1283.18)$ ng.h $/ \mathrm{mL}, 0.03( \pm 0.02) \mathrm{L} / \mathrm{h} / \mathrm{kg}$ and $2.40( \pm 0.67) \mathrm{L} / \mathrm{kg}$, respectively.

The Vd value $(2.40 \mathrm{~L} / \mathrm{kg})$ of lumefantrine is greater than the total blood volume $(0.054 \mathrm{~L} / \mathrm{kg})$ indicating extensive extravascular distribution. Furthermore, the mean hepatic blood flow in rats is approximately 3.22 $\mathrm{L} / \mathrm{h} / \mathrm{kg}$ [32]. Using the haematocrit in rat of 0.48 [32], this yields a mean hepatic plasma flow of $1.74 \mathrm{~L} / \mathrm{h} / \mathrm{kg}$. The CL value for lumefantrine $(0.03 \mathrm{~L} / \mathrm{h} / \mathrm{kg})$ represents less than $2 \%$ of the hepatic plasma flow $(1.74 \mathrm{~L} / \mathrm{h} / \mathrm{kg})$, indicating that lumefantrine is low extraction compound. Absolute oral bioavailability (\% F) of lumefantrine across the tested doses ranged between $4.80 \%$ and
$11.56 \%$. The bioavailability was decreased at higher doses. This non-linear relationship between dose and bioavailability is well described for other highly lipophilic drugs, e.g. halofantrine [33]. The variable bioavailability of lumefantrine between individual doses was also observed in humans [18]. The bioavailability of a drug determines the amount reaching the systemic circulation and it in turn determines the pharmacological effects. Hence, preclinical pharmacokinetic data will be of immense help for deciding the partner drug's dose and concentration(s) required for therapeutic efficacy in order to keep the drug's concentration at or above cidal concentration in order to prevent/delay the drug resistance at sub-cidal level.

The plasma concentrations of desbutyl-lumefantrine were measurable up to $120 \mathrm{~h}$ after oral and up to $96 \mathrm{hr}$ after intravenous administration. Figure 3 depicts the mean plasma concentration-time profiles of desbutyllumefantrine following single oral and intravenous

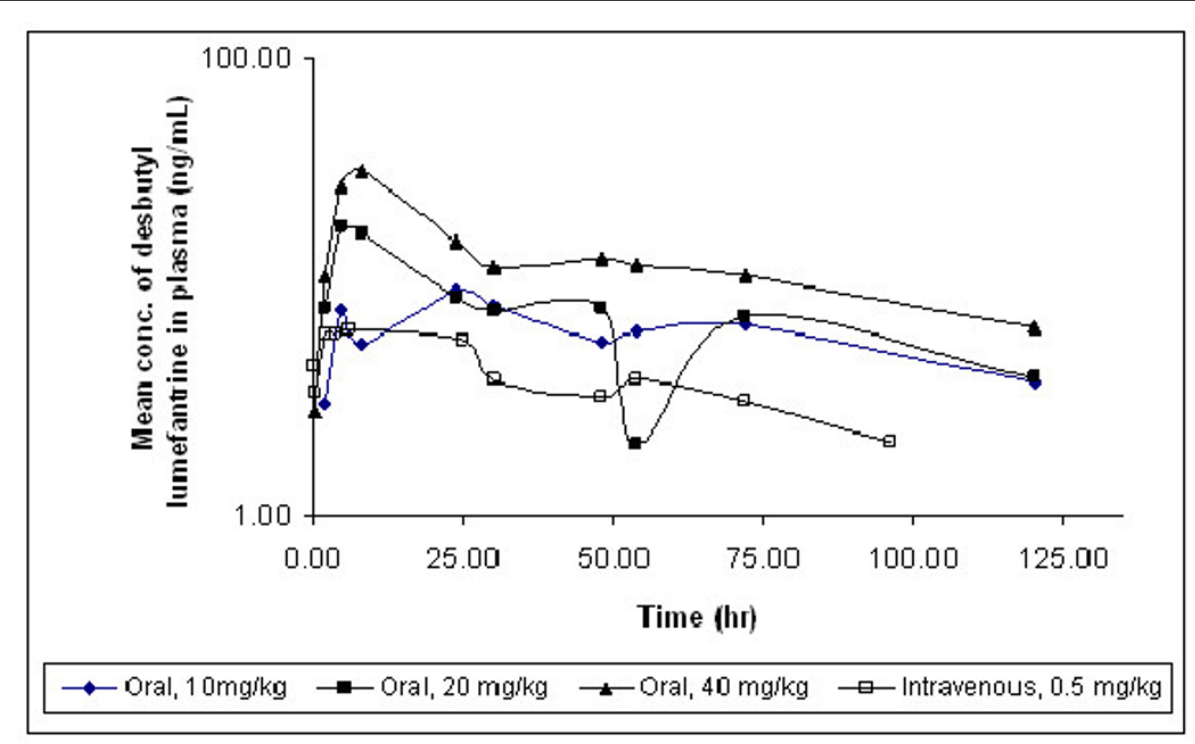

Figure 3 Plasma concentration versus time profiles of desbutyl-lumefantrine after oral and intravenous administration of lumefantrine in rats $(\mathbf{N}=4)$. All concentrations are on the logarithmic scale. 
Table 3 Pharmacokinetic parameters of desbutyl-lumefantrine after oral and intravenous administration of lumefantrine in rats

\begin{tabular}{|c|c|c|c|c|}
\hline Parameters & Intravenous & Per-oral & & \\
\hline & $0.5 \mathrm{mg} / \mathrm{kg}$ & $10 \mathrm{mg} / \mathrm{kg}$ & $20 \mathrm{mg} / \mathrm{kg}$ & $40 \mathrm{mg} / \mathrm{kg}$ \\
\hline$A \cup C_{0-t}\left(h r^{*} n g / m L\right)$ & $375.75 \pm 74.26$ & $828.18 \pm 281.31$ & $897.39 \pm 151.38$ & $1545.89 \pm 488.21$ \\
\hline$C_{\max }(\mathrm{ng} / \mathrm{mL})$ & $7.91 \pm 1.89$ & $13.54 \pm 4.27$ & $19.66 \pm 3.72$ & $34.76 \pm 17.85$ \\
\hline $\mathrm{T}_{\max }(\mathrm{hr})$ & $13.5(2-25)$ & $24(5-30)$ & $5(5-8)$ & $8(5-8)$ \\
\hline
\end{tabular}

administration of lumefantrine to male SD rats. The mean oral and intravenous pharmacokinetic parameters for desbutyl-lumefantrine are summarized in Table 3. The desbutyl-lumefantrine was detected from $2 \mathrm{hr}$ time point, except at $40 \mathrm{mg} / \mathrm{kg}$ where it was detected from first time point i.e. $0.05 \mathrm{hr}$. For nominal doses increasing in a 1:2:4 proportion, the $C_{\max }$ and $\mathrm{AUC}_{0-\mathrm{t}}$ values increased in the proportions of $1: 1.45: 2.57$ and $1: 1.08: 1.87$, respectively. Following the intravenous administration of lumefantrine, the $\mathrm{C}_{\max }$ and $\mathrm{AUC}_{0-\mathrm{t}}$ value of desbutyl-lumefantrine was found to be 7.91 ( \pm 1.89) $\mathrm{ng} / \mathrm{mL}$ and $375.75( \pm 74.26) \mathrm{ng} . \mathrm{h} / \mathrm{mL}$, respectively. In conclusion, we successfully derived the pharmacokinetic parameters of lumefantrine and its metabolite desbutyl-lumefantrine in rats for the first time. Lumefantrine displayed similar pharmacokinetics in the rat as in humans [14,18], with multiphasic disposition, low clearance, and a large volume of distribution resulting in a long terminal elimination half-life.

\section{Acknowledgements}

The authors are thankful to Director, CDRI for his constant encouragement and support. We also acknowledge Council of Scientific and Industrial Research (CSIR) for providing research fellowship to S. P. Singh.

\section{Author details}

'Pharmacokinetics and Metabolism Division, CSIR-Central Drug Research Institute, Lucknow-226001, Uttar Pradesh, India. ${ }^{2}$ Department of Pharmaceutics, National Institute of Pharmaceutical Education and Research, Rae Bareli, India. ${ }^{3}$ Parasitology Division, CSIR-Central Drug Research Institute, Lucknow-226001, Uttar Pradesh, India.

\section{Authors' contributions}

W and SPS designed and performed the experiments, analysed the data and, wrote the paper. KSRR and AN helped in performing the experiments. SKP and GKJ contributed in review of manuscript. All authors read and approved the final manuscript.

\section{Competing interests}

The authors declare that they have no competing interests.

Received: 18 March 2011 Accepted: 10 October 2011

Published: 10 October 2011

\section{References}

1. Garcia LS: Malaria. Clin Lab Med 30:93-129.

2. van Vugt M, Ezzet F, Phaipun L, Nosten F, White NJ: The relationship between capillary and venous concentrations of the antimalarial drug lumefantrine (benflumetol). Trans R Soc Trop Med Hyg 1998, 92:564-565.

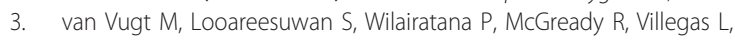
Gathmann I, Mull R, Brockman A, White NJ, Nosten F: Artemether- lumefantrine for the treatment of multidrug-resistant falciparum malaria. Trans R Soc Trop Med Hyg 2000, 94:545-548.

4. Lefevre G, Looareesuwan S, Treeprasertsuk S, Krudsood S, Silachamroon U, Gathmann I, Mull R, Bakshi R: A clinical and pharmacokinetic trial of six doses of artemether-lumefantrine for multidrug-resistant Plasmodium falciparum malaria in Thailand. Am J Trop Med Hyg 2001, 64:247-256.

5. Hatz C, Soto J, Nothdurft HD, Zoller T, Weitzel T, Loutan L, Bricaire F, Gay F, Burchard GD, Andriano K, Lefevre G, De Palacios PI, Genton B: Treatment of acute uncomplicated falciparum malaria with artemether-lumefantrine in nonimmune populations: a safety, efficacy, and pharmacokinetic study. Am J Trop Med Hyg 2008, 78:241-247.

6. Falade C, Makanga M, Premji Z, Ortmann CE, Stockmeyer M, de Palacios PI: Efficacy and safety of artemether-lumefantrine (Coartem) tablets (sixdose regimen) in African infants and children with acute, uncomplicated falciparum malaria. Trans R Soc Trop Med Hyg 2005, 99:459-467.

7. Abdulla S, Sagara I, Borrmann S, D'Alessandro U, Gonzalez R, Hamel M, Ogutu B, Martensson A, Lyimo J, Maiga H, Sasi P, Nahum A, Bassat Q, Juma E, Otieno L, Bjorkman A, Beck HP, Andriano K, Cousin M, Lefevre G, Ubben D, Premji Z: Efficacy and safety of artemether-lumefantrine dispersible tablets compared with crushed commercial tablets in African infants and children with uncomplicated malaria: a randomised, singleblind, multicentre trial. Lancet 2008, 372:1819-1827.

8. Dorsey G, Staedke S, Clark TD, Njama-Meya D, Nzarubara B, MaitekiSebuguzi C, Dokomajilar C, Kamya MR, Rosenthal PJ: Combination therapy for uncomplicated falciparum malaria in Ugandan children: a randomized trial. Jama 2007, 297:2210-2219.

9. Zongo I, Dorsey G, Rouamba N, Tinto H, Dokomajilar C, Guiguemde RT, Rosenthal PJ, Ouedraogo JB: Artemether-lumefantrine versus amodiaquine plus sulfadoxine-pyrimethamine for uncomplicated falciparum malaria in Burkina Faso: a randomised non-inferiority trial. Lancet 2007, 369:491-498.

10. Premji ZG: Coartem: the journey to the clinic. Malar J 2009, 8(Suppl 1):S3.

11. White NJ: Preventing antimalarial drug resistance through combinations. Drug Resist Updat 1998, 1:3-9.

12. Bunnag D, Viravan C, Looareesuwan S, Karbwang J, Harinasuta T: Clinical trial of artesunate and artemether on multidrug resistant falciparum malaria in Thailand. A preliminary report. Southeast Asian J Trop Med Public Health 1991, 22:380-385.

13. Kokwaro G, Mwai L, Nzila A: Artemether/lumefantrine in the treatment of uncomplicated falciparum malaria. Expert Opin Pharmacother 2007 8:75-94.

14. White NJ, van Vugt M, Ezzet F: Clinical pharmacokinetics and pharmacodynamics and pharmacodynamics of artemether-lumefantrine. Clin Pharmacokinet 1999, 37:105-125.

15. Golenser J, Waknine JH, Krugliak M, Hunt NH, Grau GE: Current perspectives on the mechanism of action of artemisinins. Int J Parasitol 2006, 36:1427-1441.

16. Hassan Alin M, Bjorkman A, Wernsdorfer WH: Synergism of benflumetol and artemether in Plasmodium falciparum. Am J Trop Med Hyg 1999, 61:439-445.

17. Efferth T: Willmar Schwabe Award 2006: antiplasmodial and antitumor activity of artemisinin-from bench to bedside. Planta Med 2007, 73:299-309.

18. Ezzet F, van Vugt M, Nosten F, Looareesuwan S, White NJ: Pharmacokinetics and pharmacodynamics of lumefantrine (benflumetol) in acute falciparum malaria. Antimicrob Agents Chemother 2000, 44:697-704.

19. Ashley EA, Stepniewska K, Lindegardh N, Annerberg A, Kham A, Brockman A, Singhasivanon P, White NJ, Nosten F: How much fat is 
necessary to optimize lumefantrine oral bioavailability? Trop Med Int Health 2007, 12:195-200.

20. Ashley EA, Stepniewska K, Lindegardh N, McGready R, Annerberg A, Hutagalung R, Singtoroj T, Hla G, Brockman A, Proux S, Wilahphaingern J, Singhasivanon P, White NJ, Nosten F: Pharmacokinetic study of artemether-lumefantrine given once daily for the treatment of uncomplicated multidrug-resistant falciparum malaria. Trop Med Int Health 2007, 12:201-208.

21. Noedl H, Allmendinger T, Prajakwong S, Wernsdorfer G, Wernsdorfer WH: Desbutyl-benflumetol, a novel antimalarial compound: in vitro activity in fresh isolates of Plasmodium falciparum from Thailand. Antimicrob Agents Chemother 2001, 45:2106-2109.

22. Vugt MV, Wilairatana P, Gemperli B, Gathmann I, Phaipun L, Brockman A, Luxemburger C, White NJ, Nosten F, Looareesuwan S: Efficacy of six doses of artemether-lumefantrine (benflumetol) in multidrug-resistant Plasmodium falciparum malaria. Am J Trop Med Hyg 1999, 60:936-942.

23. Ezzet F, Mull R, Karbwang J: Population pharmacokinetics and therapeutic response of CGP 56697 (artemether + benflumetol) in malaria patients. Br J Clin Pharmacol 1998, 46:553-561.

24. Denis MB, Tsuyuoka R, Lim P, Lindegardh N, Yi P, Top SN, Socheat D, Fandeur T, Annerberg A, Christophel EM, Ringwald P: Efficacy of artemether-lumefantrine for the treatment of uncomplicated falciparum malaria in northwest Cambodia. Trop Med Int Health 2006, 11:1800-1807.

25. Colussi D, Parisot $C$, Legay F, Lefevre G: Binding of artemether and lumefantrine to plasma proteins and erythrocytes. Eur J Pharm Sci 1999, 9:9-16.

26. Wernsdorfer WH: Coartemether (artemether and lumefantrine): an oral antimalarial drug. Expert Rev Anti Infect Ther 2004, 2:181-196.

27. Wong RP, Salman S, llett KF, Siba PM, Mueller I, Davis TM: Desbutyllumefantrine is a metabolite of lumefantrine with potent in vitro antimalarial activity that may influence artemether-lumefantrine treatment outcome. Antimicrob Agents Chemother 2011, 55:1194-1198.

28. Xing J, Bai KH, Liu T, Wang RL, Zhang LF, Zhang SQ: The multiple-dosing pharmacokinetics of artemether, artesunate, and their metabolite dihydroartemisinin in rats. Xenobiotica 2011, , 41: 252-258.

29. Fagerholm U, Johansson M, Lennernas H: Comparison between permeability coefficients in rat and human jejunum. Pharm Res 1996, 13:1336-1342

30. Komiya I, Park JY, Kamani A, Ho NFH, Higuchi WI: Quantitative mechanistic studies in simultaneous fluid flow and intestinal absorption using steroids as model solutes. Int J Pharm 1980, 4:249-262.

31. Singh SP, Jain GK: Determination of lumefantrine in rat plasma by liquidliquid extraction using LC-MS/MS with electrospray ionization: assay development, validation and application to a pharmacokinetic study. J Chromatogr B Analyt Technol Biomed Life Sci 2009, 877:1133-1139.

32. Davies B, Morris T: Physiological parameters in laboratory animals and humans. Pharm Res 1993, 10:1093-1095.

33. Ohrt C, Watt G, Teja-Isavadharm P, Keeratithakul D, Loesuttiviboon L, Webster HK, Schuster B, Fleckenstein L: Pharmacokinetics of an extendeddose halofantrine regimen in patients with malaria and in healthy volunteers. Clin Pharmacol Ther 1995, 57:525-532.

doi:10.1186/1475-2875-10-293

Cite this article as: Wahajuddin et al:: Intravenous pharmacokinetics, oral bioavailability, dose proportionality and in situ permeability of antimalarial lumefantrine in rats. Malaria Journal 2011 10:293.

\section{Submit your next manuscript to BioMed Central and take full advantage of:}

- Convenient online submission

- Thorough peer review

- No space constraints or color figure charges

- Immediate publication on acceptance

- Inclusion in PubMed, CAS, Scopus and Google Scholar

- Research which is freely available for redistribution

Submit your manuscript at www.biomedcentral.com/submit
Biomed Central 